\title{
Superior vena caval obstruction in total anomalous pulmonary venous connexion
}

\author{
P. Syamasundar Rao and Daniel R. Silbert
}

From the Department of Pediatrics, University Hospitals of Cleveland and Case-Western Reserve University School of Medicine, Cleveland, Ohio, U.S.A.

An unusual case of total anomalous pulmonary venous connexion with physiologically and anatomically proven obstruction at the level of the superior vena cava is described. The embryological basis for this defect is briefly discussed. The types of anatomical obstruction to supradiaphragmatic total anomalous pulmonary venous connexion are reviewed and classified.

Total anomalous pulmonary venous connexion may be conveniently classified into supradiaphragmatic and infradiaphragmatic types (Smith, Frye, and Newton, 1961). Infradiaphragmatic forms are usually associated with obstruction to pulmonary venous flow (Johnson et al., 1958) and the supradiaphragmatic types are said only rarely to have pulmonary venous obstruction (Lucas et al., 1963). However, obstruction to pulmonary blood flow has been described in the latter type and lately increasing attention has been given to this factor. The purpose of this report is to document an unusual type of obstruction to pulmonary venous blood flow in a case of supradiaphragmatic total anomalous pulmonary venous connexion. The possible embryological origin of this defect and the types of obstruction seen in the supradiaphragmatic form will also be discussed.

\section{Case report}

A male infant of 2 months was admitted to the Babies and Childrens Hospital with congestive heart failure and cyanosis. He was the product of a full-term normal pregnancy and delivery. Physical examination revealed a tachypnoeic infant with mild to moderate cyanosis. The heart rate was 180 and the blood pressure was $100 / 60$

TABLE Cardiac catheterization data

\begin{tabular}{|c|c|c|}
\hline Site & $\begin{array}{l}\text { Saturation } \\
(\%)\end{array}$ & $\begin{array}{l}\text { Pressure } \\
(\mathrm{mmHg})\end{array}$ \\
\hline $\begin{array}{l}\text { Left innominate vein } \\
\text { Inferior vena cava (low) } \\
\text { Inferior vena cava (high) } \\
\text { Azygous vein (near diaphragm) } \\
\text { Superior vena cava } \\
\text { Right atrium (mid) } \\
\text { Right ventricle } \\
\text { Left pulmonary artery } \ddagger \\
\text { Left atrium } \\
\text { Femoral artery } \ddagger\end{array}$ & $\begin{array}{l}39 \\
73 \\
87 \\
90 \\
97 \\
97 \\
93 \\
93(85) \\
93 \\
90(82)\end{array}$ & $\begin{array}{l}- \\
a=14, v=9, m=7 \\
- \\
a=25, v=27, m=19 \dagger \\
a=14, v=9, m=7 \dagger \\
94 / 11 \\
90 / 30, m=52 \\
a=12, v=8, m=5 \\
90 / 60, m=73\end{array}$ \\
\hline $\begin{array}{l}\text { After balloon atrioseptostomy } \\
\text { Left atrium } \\
\text { Right atrium }\end{array}$ & 二 & $\begin{array}{l}a=10, v=7, m=4.5 \\
a=11, v=9, m=5\end{array}$ \\
\hline
\end{tabular}

* Obtained while the infant was placed under a hood with 100 per cent oxygen. Values in parentheses were obtained while in room air.

† Obtained from a withdrawal tracing from the superior vena cava to right atrium. $\ddagger$ Simultaneously measured. 


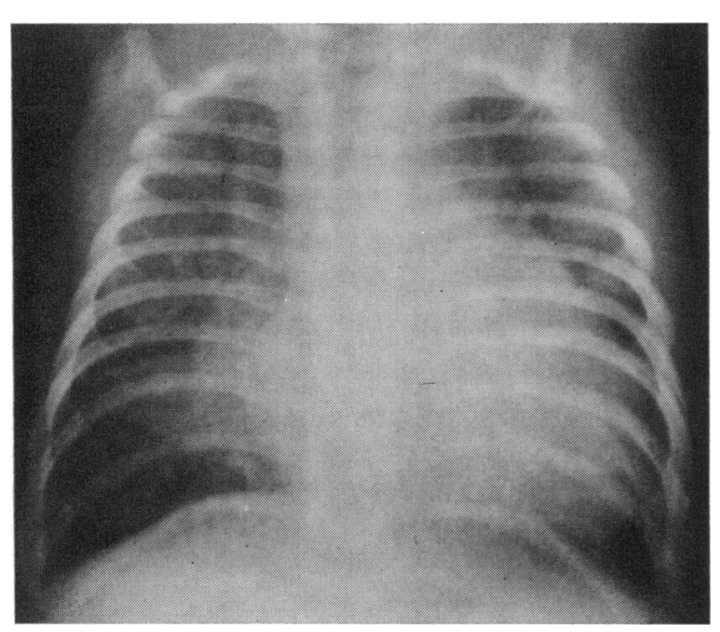

FIG. I Posteroanterior view of the chest showing moderate cardiomegaly and increased pulmonary vascular markings.

mmHg. The liver was palpable $5 \mathrm{~cm}$ below the right costal margin. The praecordium was hyperdynamic with a prominent right ventricular impulse. The first heart sound was normal and the second heart sound narrowly split. There was a grade $2 / 6$ ejection systolic murmur at the left upper sternal border, and a grade $2 / 6$ middiastolic rumble at the left lower sternal border.

Chest $x$-ray showed moderate cardiomegaly and increased pulmonary vascularity (Fig. I). The electrocardiogram (Fig. 2) showed right ventricular and right atrial hypertrophy. After initial treatment for congestive heart failure, cardiac catheterization (Table) and selective
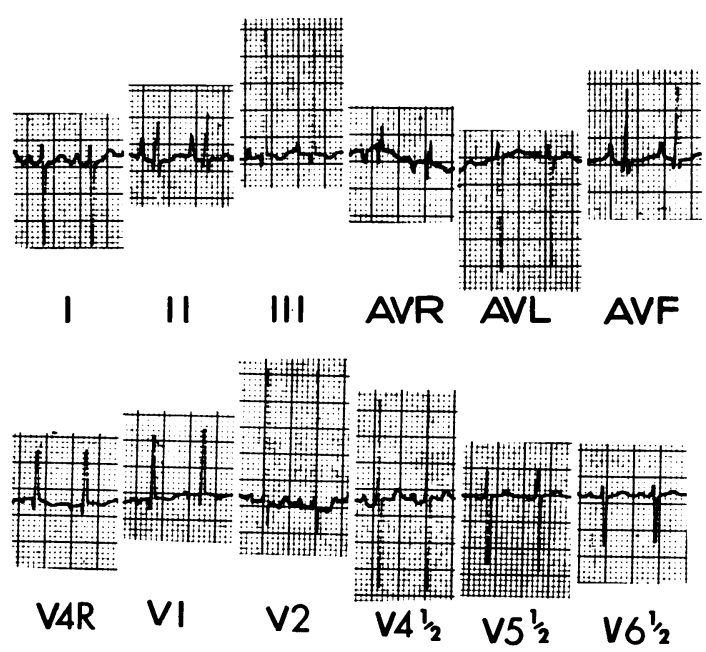

FIG. 2 Standard electrocardiogram showing right ventricular and right atrial hypertrophy. cineangiography were performed. There was a conspicuous difference between the pressures in the right atrium and in the superior vena cava, determined by direct pullback. After a main pulmonary artery injection, the pulmonary venous return was faint and a definite common pulmonary trunk was not visualized. But the superior vena cava was first opacified and the right atrium subsequently. A superior vena caval angiogram showed retrograde filling of the azygous vein (Fig. 3), with subsequent opacification of inferior vena cava and then the right atrium. Only a small amount of contrast passed from the superior vena cava to the right atrium. Attempts to enter the pulmonary vein from the superior vena cava were unsuccessful, and, hence, additional pressure gradient from the common pulmonary vein to the superior vena cava cannot be ruled out. A Rashkind's balloon atrioseptostomy was performed which abolished the interatrial pressure gradient (Table). Medical treatment of cardiac failure was continued. Because of persistent heart failure and lack of weight gain, at the age of 5 months, surgical relief of the superior vena caval obstruction was sought. At operation the superior vena cava is noted to be inserted into the right atrium in a more posterior position than normal. A linear vertical incision was made at the right atrial and superior vena caval junction which was closed in a transverse fashion like a HeinckeMickulicz repair of the intestine, by which the pressures

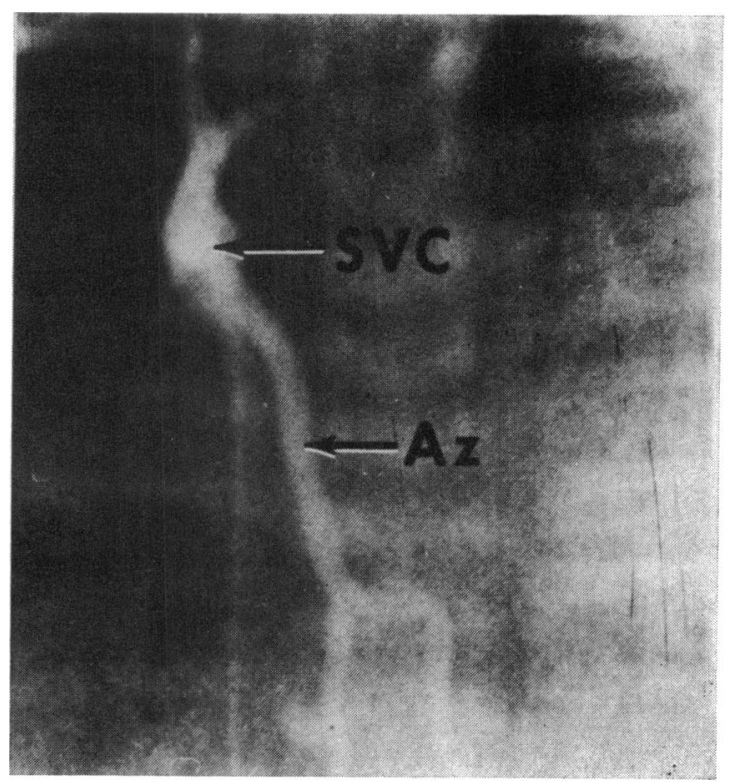

FIG. 3 Superior vena caval angiogram in posteroanterior projection shows prompt opacification of the azygous vein. Note absence of right atrial opacification. In the cineangiogram, the inferior vena cava was filled with contrast subsequent to azygous opacification and then the right atrium. Az, Azygous vein; $S V C$, superior vena cava. 


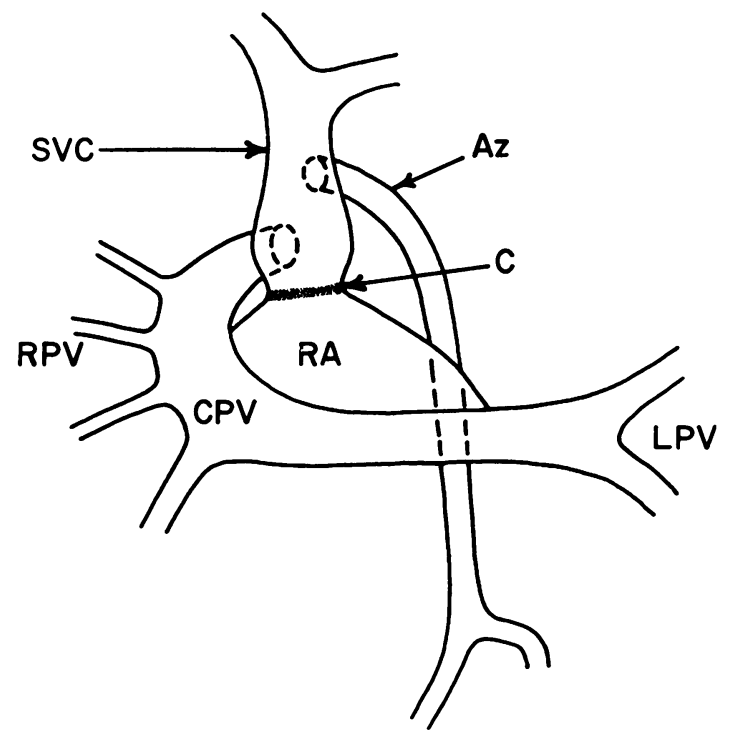

FIG. 4 Diagrammatic sketch of the pulmonary venous return. Two pulmonary veins draining the left lung join to form the common left pulmonary vein which traverses to the right and then ascends to empty in the posterolateral aspect of the superior vena cava. Into the lateral convexity of the common pulmonary vein empty four right pulmonary veins. The position of the azygous opening into the superior vena cava and the constricted area of the superior vena cava (arrow) are also shown.

$A z$, azygous vein; $C$, constricted area of the superior vena cava; CPV, common pulmonary vein; $L P V$, left pulmonary veins; $R A$, right atrium; $R P V$, right pulmonary veins; $S V C$, superior vena cava.

in the superior vena cava and right atrium were equalized. The infant improved, but the next morning he suddenly deteriorated and died.

Necropsy findings were limited to the cardiovascular system and lungs. The heart was minimally enlarged with right ventricular and pulmonary arterial enlargement. The left atrium and the left ventricle were normal in size. The pulmonary venous drainage is diagramatically represented in Fig. 4. The left lung was drained by two pulmonary veins which joined behind the heart; this common left pulmonary vein traversed across the midline and ascended superiorly to join the posterolateral aspect of the superior vena cava. The right lung was drained by four small but probably adequate-sized veins into the lateral convexity of the common pulmonary trunk (Fig. 4). The opening of the common pulmonary venous trunk into the superior vena cava was of adequate size and its orifice is situated inferior to the opening of the azygous vein. There was a ring-like fibrous constriction at the junction of superior vena cava with the right atrium which was partially enlarged by surgery. There was some dilatation of the superior vena cava immediately above this constriction. There was anomalous lobulation of the right lung. The pulmonary vasculature showed grade II changes (HeathEdwards) on histological examination.

\section{Discussion}

The case presented had total anomalous pulmonary venous connexion to the superior vena cava, with physiologically and anatomically proven obstruction at the junction of the superior vena cava with the right atrium. Recently Shadravan et al. (1971) reported a case in which the pulmonary veins from the left lung and the right lower lobe drained into a chamber behind the right atrium with minute communication with the right atrium, and the right superior pulmonary vein entered the superior vena cava below the entrance of the azygous vein. There was a stenotic ring in the superior vena cava inferior to the opening of the anomalous pulmonary vein. The superior vena caval obstruction appears to be similar to that in our case and the retrograde flow in the azygous vein in both cases is characteristic of superior vena caval obstruction (Steinberg, 1962). The other cases reported, with obstructed total anomalous pulmonary vein connexion to the superior vena cava, had stenosis of the common pulmonary venous trunk at its entrance into the superior vena cava (Scott and Welch, 1965; Bonham Carter, Capriles, and Noe, I969; Gathman and Nadas, 1970).

The embryological defect in total anomalous pulmonary venous connexion is atresia of the common pulmonary vein (Lucas et al., 1963; Moss and Adams, 1968; Neil, 1956). This results in persistence of the primitive venous connexions between the primordial splanchnic vascular bed (future pulmonary vascular bed) and the cardinal veins (Lucas et al., 1963; Moss and Adams, 1968; Neil, 1956; Patten, 1968). The origin of the superior vena caval obstruction is unknown. Embryologically, the superior vena cava is derived from right common cardinal vein (caudal portion) and right anterior cardinal vein (cephalic part) (Moss and Adams, I968; Patten, 1968). The right common cardinal vein empties into the right horn of the sinus venosus. The right horn of the sinus venosus later becomes incorporated into the right atrium. A circular constriction at the junction of the common cardinal vein with the sinus venosus during the embryonic period may explain the superior vena cava constriction. The constriction may have formed at the time of or after the establishment of connexion of the right common cardinal vein with the sinus venosus or may be due to inadequate canalization at their 
junction. The other possibility is the persistence of the venous valves. The valvulae venosae merge cephalo-dorsally to form the septum spurium (normally all these structures are resorbed leaving the crista terminalis, the Eustachian valve of the inferior vena cava, and the Thebesian valve of the coronary sinus as the only remnants). If the cephalic portion of the venous valves and septum spurium persist around the opening of right common cardinal vein (future superior vena cava), the constriction of the superior vena cava at its junction with the right atrium as in our case may be the result.

Although the classification of total anomalous pulmonary venous connexion using embryological (Neil, I956) or anatomical (Smith et al., I96I; Darling, Rothney, and Craig, 1957; Burroughs and Edwards, 1960) features is conventional, the greater recognition of the importance of pulmonary venous obstruction resulted in a physiological classification of this entity namely with or without pulmonary venous obstruction. The clinical features and the surgical mortality are intimately related to the presence of pulmonary venous obstruction. Pulmonary venous obstruction is the rule in the infradiaphragmatic total anomalous pulmonary venous connexion and is caused I) by extrinsic obstruction at the level of diaphragm, 2) by closure of the ductus venosus, 3 ) by high resistance to the passage of blood through the liver sinusoids, or 4) by intrinsic stenosis of the connecting vein (Johnson et al., 1958; Levin and White, 196r; Lucas et al., 196I, 1963). A long connecting vein itself may offer impedance to the pulmonary venous return (Bonham Carter et al., 1969).

Review of the published reports revealed that pulmonary venous obstruction may occur in all types of total anomalous pulmonary venous connexion above the diaphragm and these will be summarized here. The nature of the obstruction in cases with anomalous connexion to the superior vena cava has already been discussed. Hauck, Rudolph, and Nadas (1960) reported a case with common pulmonary vein draining into the azygous vein in which the connecting vessel was small and narrow, resulting in obstruction. In another case with azygous connexion, the nature of the obstruction was not detailed (Harris, Neuhauser, and Giedion, 1960). Obstruction to total anomalous pulmonary venous connexion into the anomalous vertical vein (Didion, I942; Burroughs and Edwards, 1960; Hauck et al., 1960; Harris et al., 1960; Kauffman, Ores, and Andersen, 1962; Elliot and Edwards, 1962; Hastreiter et al., 1962; Carey and Edwards, 1963; Bonham Carter et al., 1969; Gathman and Nadas, 1970) may be due to intrinsic stenosis or extrinsic compression. The intrinsic obstruction can result from stenosis of the anomalous vertical vein at its juntion with the common pulmonary vein (Kauffman et al., 1962; Hastreiter et al., 1962; Carey and Edwards, 1963) or at its junction with the left innominate vein (Hauck et al., 1960) or may be due to narrowed left innominate vein (Bonham Carter et al., 1969). The extrinsic obstruction appears to be due to compression of the anomalous vertical vein as it passes between left pulmonary artery and left bronchus (Didion, 1942; Kauffman et al., 1962; Elliot and Edwards, 1962 ; Carey and Edwards, 1963; Bonham Carter et al., 1969; Gathman and Nadas, 1970). It is in the latter situation that the pulmonary venous obstruction has been described as a 'haemodynamic vice' (Elliot and Edwards, 1962). Compression of the vertical vein results in increased pulmonary arterial pressure and thereby increased distension of the pulmonary artery which in turn accentuates the pulmonary venous obstruction and thus a vicious circle occurs. Two cases with connexion to the right atrium had atresia of the vessel connecting the pulmonary vein and right atrium (Lucas et al., 1962; Edwards et al., 1965), and in a third case (Nakib et al., 1967) there was stenosis of the common pulmonary vein at its junction with the right atrium. In cases with drainage into the coronary sinus, one case had stenosis at the junction of the pulmonary venous confluence with the coronary sinus (Lucas et al., 1963), and in the other case there was stenosis of the individual pulmonary veins before their entrance into the coronary sinus (Gathman and Nadas, 1970).

Sometimes the common pulmonary trunk may not make any effective communication with the systemic veins (Bonham Carter et al., 1969; Hastreiter et al., 1962; Lucas et al., 1962). Strictly speaking, this malformation, blind common pulmonary trunk, is not a form of total anomalous pulmonary venous connexion but it is embryologically very close to and clinically very similar to it. Another important site of obstruction is at the level of the atrial septum (Burroughs and Edwards, 1960), and this could be treated with balloon atrioseptostomy (Miller et al., 1967; Seratto et al., 1967, 1968). Thus the obstruction to pulmonary venous return in cases with total anomalous pulmonary venous connexion may be divided into I) obstructing atrial septum, 2) extrinsic compression, and 3) intrinsic stenosis or atresia.

Pulmonary venous obstruction occurs more frequently than has been previously recognized; a recent review of the physiological aspects of 75 cases (Gathman and Nadas, 1970) clearly points to this fact. Of the 75 cases (all types), 52 had pulmonary arterial hypertension (defined as right ventricular-pulmonary arterial pressure greater 
than one-half of the systemic pressure), and of these, $40(53 \%$ of all cases and $41 \%$ of cases of the supradiaphragmatic type) had pulmonary venous obstruction. Though it is not the purpose of this paper to discuss the differential diagnosis, it is worth while to note that the pulmonary venous obstructive picture in cases with stenosis of pulmonary veins, cor triatriatum, mitral atresia, supravalvular stenosing ring of the left atrium, and pulmonary veno-occlusive disease cannot be clinically distinguished from total anomalous pulmonary venous connexion with pulmonary venous obstruction.

\section{References}

Bonham Carter, R. E., Capriles, M., and Noe, Y. (1969). Total anomalous pulmonary venous drainage. British Heart fournal, 31, 45.

Burroughs, J. T., and Edwards, J. E. (1960). Total anomalous pulmonary venous connection. American Heart fournal, 59, 913.

Carey, L. S., and Edwards, J. E. (1963). Severe pulmonary venous obstruction in total anomalous pulmonary venous connection to the left innominate vein. American fournal of Roentgenology, 90, 593.

Darling, R. C., Rothney, W. B., and Craig, J. M. (1957). Total pulmonary venous drainage into the right side of the heart: report of 17 autopsied cases not associated with other major cardiovascular anomalies. Laboratory Investigation, 6, 44.

Didion, H. (1942). Uber Missbildungen des rechten Vorhofes, seiner Venen sowie der Lungenevenen. Virchows Archiv für pathologische Anatomie und Physiology, 309, I.

Edwards, J. E., Carey, L. S., Neufeld, H. N., and Lester, R. G. (1965). Congenital Heart Disease, p. 539. W. B. Saunders, Philadelphia.

Elliot, L. P., and Edwards, J. E. (1962). The problem of pulmonary venous obstruction in total anomalous pulmonary venous connection to the left innominate vein. Circulation, $25,913$.

Gathman, G. E., and Nadas, A. S. (1970). Total anomalous pulmonary venous connection: clinical and physiologic observations of 75 pediatric patients. Circulation, 42, 143.

Harris, G. B. C., Neuhauser, E. B. D., and Giedion, A. (1960). Total anomalous pulmonary venous return below the diaphragm: the roentgen appearances in three patients diagnosed during life. American fournal of Roentgenology, 84, 436 .

Hastreiter, A. R., Paul, M. H., Molthan, M. E., and Miller, R. A. (1962). Total anomalous pulmonary venous connection with severe pulmonary venous obstruction: a clinical entity. Circulation, 25, 916.

Hauck, A. J., Rudolph, A. M., and Nadas, A. S. (1960). Pulmonary venous obstruction in infants with anomalous pulmonary venous drainage (abstract). American fournal of Diseases of Children, 100, 744.

Johnson, A. L., Wiglesworth, F. W., Dunbar, J. S., Siddoo, S., and Grajo, M. (1958). Infradiaphragmatic total anomalous pulmonary venous connection. Circulation, 17 340.

Kauffman, S. L., Ores, C. N., and Andersen, D. H. (I962). Two cases of total anomalous pulmonary venous return of the supracardiac type with stenosis simulating infradiaphragmatic drainage. Circulation, 25, 376.

Levin, B., and White, H. (196I). Total anomalous pulmonary venous drainage into the portal system. Radiology, 76, 894 .

Lucas, R. V., Jr., Adams, P., Jr., Anderson, R. C., Varco, R. L., Edwards, J. E., and Lester, R. G. (I96I). Total anomalous pulmonary venous connection to the portal venous system: a cause of pulmonary venous obstruction. American fournal of Roentgenology, 86, 56r.

Lucas, R. V., Jr., Anderson, R. C., Amplatz, K., Adams, P., Jr., and Edwards, J. E. (1963). Congenital causes of pulmonary venous obstruction. Pediatric Clinics of North America, 10, 781.

Lucas, R. V., Jr., Woolfrey, B. F., Anderson, R. C., Lester, R. G., and Edwards, J. E. (1962). Atresia of the common pulmonary vein. Pediatrics, 29, 729.

Miller, W. W., Rashkind, W. J., Miller, R. A., Hastreiter, A. R., Green, E. W., Golinko, R. J., and Young, D. (1967). Total anomalous pulmonary venous return: effective palliation of critically ill infants by balloon atrial septotomy (abstract). Circulation, 36, Suppl. 2, 189.

Moss, A. J., and Adams, F. H. (1968). Heart Disease in Infants, Children, and Adolescents, pp. I-25, 672-727. Williams and Wilkins, Baltimore.

Nakib, A., Moller, J. H., Kanjuh, V. I., and Edwards, J. E. (1967). Anomalies of the pulmonary veins. American fournal of Cardiology, 20, 77.

Neil, C. A. (1956). Development of the pulmonary veins: with reference to the embryology of anomalies of pulmonary venous return. Pediatrics, 18, 880.

Patten, B. M. (1968). Human Embryology, 3rd ed., p. 500. McGraw-Hill, New York.

Scott, L. P., III, and Welch, C. C. (1965). Factors influencing survival in total anomalous pulmonary venous drainage in infants. American fournal of Cardiology, 16, 286.

Seratto, M., Bucheleres, H. G., Arevalo, F., Hastreiter, A. R., and Miller, R. A. (1967). Total anomalous pulmonary venous connection without obstruction: hemodynamic and prognostic importance of foramen ovale size (abstract). Circulation, 36, Suppl. 2, 232.

Seratto, M., Bucheleres, H. G., Bicoff, P., Miller, R. A., and Hastreiter, A. R. (1968). Palliative balloon atrial septostomy for total anomalous pulmonary venous connection in infancy. Fournal of Pediatrics, 73, 734 .

Shadravan, I., Baucum, R., Fowler, R. L., Villadiego, R., and Puyau, F. A. (197I). Obstructed anomalous pulmonary venous return. American Heart fournal, 82, 232.

Smith, B., Frye, T. R., and Newton, W. A., Jr. (I96I). Total anomalous pulmonary venous return: diagnostic criteria and a new classification. American fournal of Diseases of Children, 101, $4 \mathrm{I}$.

Steinberg, I. (I962). Dilatation of the hemiazygos veins in superior vena caval occlusion simulating mediastinal tumor. American fournal of Roentgenology, 87, 248.

Requests for reprints to Dr. P. S. Rao, Department of Pediatrics, Medical College of Georgia, Augusta, Georgia 30902, U.S.A. 